\title{
AN UNIDENTIFIED THEOLOGICAL FRAGMENT FROM THE FIFTH CENTURY IN A PRIVATE COLLECTION IN CAMBRIDGE (DE HAMEL MS 373)
}

\author{
Peter M. Head
}

\section{Introduction}

This small fragment of a Christian text was purchased early in 2003 along with other small portions of Greek manuscripts on parchment which all turned out to be manuscripts of the Greek Bible. ${ }^{1}$ Like the other texts, it appears to have been cut and re-used in the binding or repair of other manuscripts. This small square piece of text measures slightly less than 4 by 3 centimetres, and has only four clear lines of text (with some traces of a line above the first readable one), without any extant margin or edge. Most of the text is easily readable (at least on one side).

The hand may be described as a biblical majuscule, quite similar in style and general appearance to Codex Alexandrinus, and to be dated quite confidently to the fifth century. ${ }^{2}$ Alongside a transcription we have reproduced high-quality long-exposure UV photographs of the manuscript. ${ }^{3}$

\footnotetext{
1 For a preliminary report based on a presentation to the Cambridge Senior New Testament Seminar see: P. M. Head, 'Fragments of Six Newly Identified Greek Bible Manuscripts in a Cambridge Collection: A Preliminary Report', in: TC: A Journal of Biblical Textual Criticism [see http://purl.org/TC] 8 (2003). P. M. Head, 'A New Manuscript of Jeremiah in Greek according to the Lucianic Recension (de Hamel MS 391; Rahlfs 897)', BIOSCS 36 (2003): 27-37 [publication date 2004] (the opening two paragraphs cover similar ground). For the NT manuscripts see P. M. Head, 'Five New Testament Manuscripts in a Cambridge Collection' (forthcoming).

2 For other comparable manuscripts of this era see G. Cavallo \& H. Maehler, Greek Bookhands of the Early Byzantine Period A.D. 300-800 (BICS Supp. 47; London: Institute of Classical Studies, 1987): 24 a-c.

3 Thanks for the photographs are due to Mark Scudder of the photographic department of the Cambridge University Library.
} 


\section{Side A}

traces visible

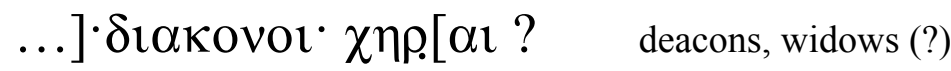

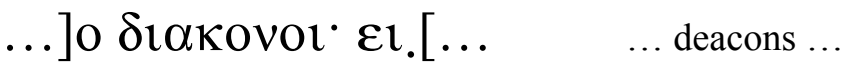

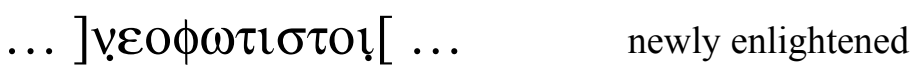

...] $\tau \omega \varsigma$ ol $\gamma \varepsilon \rho o v[\tau \varepsilon \varsigma$ ? those who are married (?)

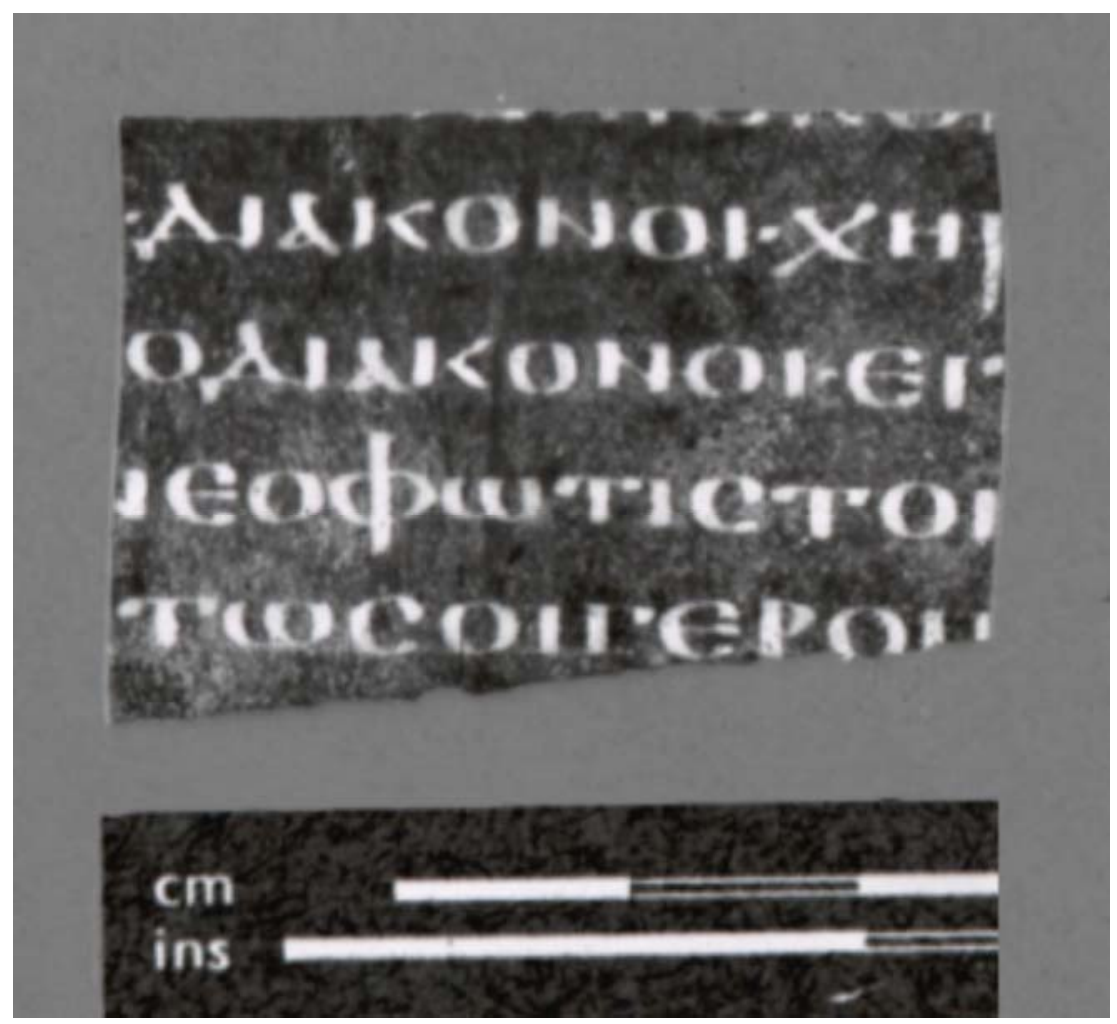




\section{Side B}

traces visible

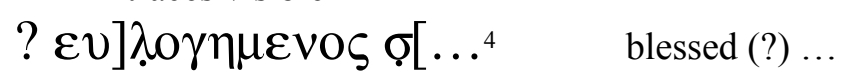

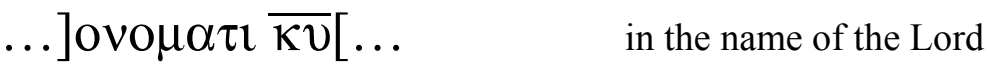

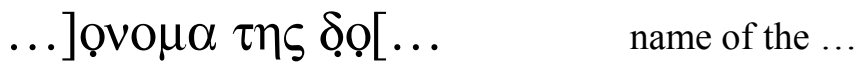

$\ldots] . . . \pi \alpha \varsigma . .[\ldots \quad \ldots$ all/every ...

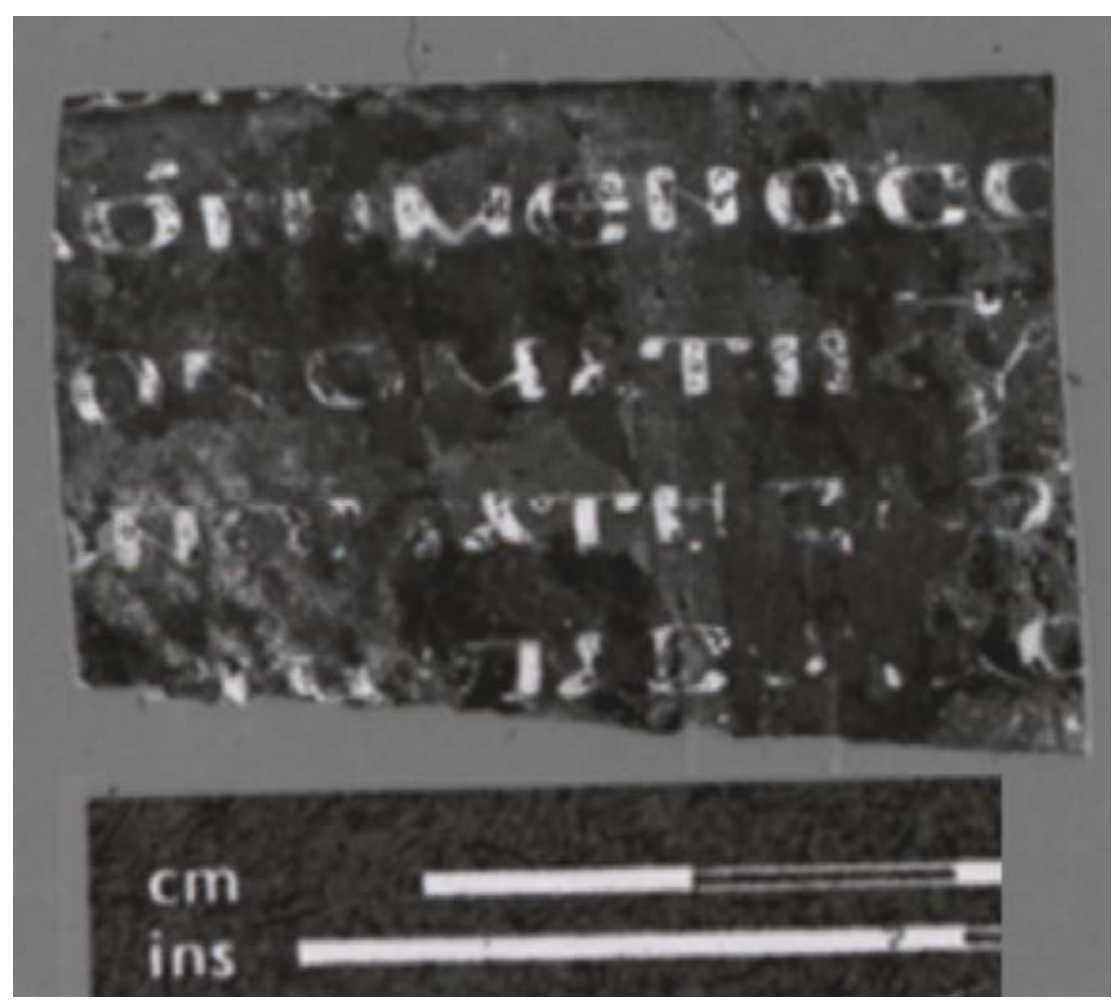

4 Line 1: possibly: ó $\mu \circ \lambda \circ \gamma \eta \mu \varepsilon v o \varsigma$ or $\varepsilon \dot{\lambda} \lambda \circ \gamma \eta \mu \varepsilon v o \varsigma$. 


\section{Analysis}

The vocabulary and the use of a nomen sacrum for kúpros suggest Christian content, possibly involving a discussion of church order, or a list of offices or church personnel. Repeated and varied searches on the Thesaurus Linguae Graecae: A Digital Library of Greek Literature, where searches on different word or letter combinations in association can be attempted on virtually all ancient Greek literature, have failed to turn up any match. ${ }^{5}$

5 Although the task of identifying the fragment has proven unsuccessful I acknowledge the help and encouragement of Dirk Jongkind, Peter J. Williams, Simon Gathercole, and Thomas Graumann in the process. 